\title{
ESTUDIO CLÍNICO, SEROLÓGICO Y PATOLÓGICO DE UNA CEPA VELOGÉNICA DEL VIRUS DE NEWCASTLE EN CODORNICES (Coturnix coturnix japonica)
}

\author{
Clinical, Serological and Pathological Study of a Newcastle Velogenic \\ Virus Strain in QuaILs (Coturnix Coturnix Japonica)
}
Tatiana Quevedo C. ${ }^{1}$, Eliana Icochea D. ${ }^{1,2}$, Mónica Alba Ch. ${ }^{1}$, Nieves Sandoval Ch. ${ }^{3}$ y Raúl Rosadio A. ${ }^{4}$

\section{Resumen}

Se determinó la susceptibilidad, el efecto patológico, y la respuesta serológica inducida por una cepa velogénica viscerotrópica del virus de la enfermedad de Newcastle (vvENC). Para este fin, se criaron 40 codornices japónicas (Coturnix coturnix japonica) hembras, donde 20 se inocularon vía nasal y ocular con una cepa de vvENC y 20 se usaron como grupo control. Para el análisis histopatológico y recuperación viral se tomó muestras de tejidos e hisopados de cloaca de las aves inoculadas y del grupo control; y para detectar anticuerpos contra el virus de la ENC mediante la prueba de inhibición de la hemaglutinación ( $\mathrm{IH})$ se tomó muestras de sangre durante 5 semanas posteriores al desafío. En el $40 \%$ de las aves inoculadas se registraron signos severos, así como mortalidad del 20\% de las aves inoculadas. Del mismo modo, se registraron lesiones macroscópicas y microscópicas en los animales inoculados. El grupo desafiado registró un incremento en los niveles de anticuerpos a partir de los 7 días postinoculación (PGT 6.1), alcanzando el mayor PGT a los 14 días post inoculación (PGT 29.9), mientras que en el grupo de aves control no se registró seroconversiones. La recuperación viral se logró a partir de los hisopados de cloaca de las aves afectadas por la enfermedad. El grupo control no registró signos de enfermedad ni cambios histopatológicos.

Palabras clave: enfermedad de Newcastle, codorniz japónica, signos clínicos, histopatología, niveles de anticuerpos, recuperación viral

\section{Abstract}

The objective of the study was to determine the susceptibility, pathological effect, and serological response induced by a velogenic viscerotropic strain of Newcastle disease virus (vvNDV). For this purpose, 40 female quails (Coturnix coturnix japonica) were raised. Twenty were nasal and ocular inoculated with a vVNDV strain and 20 remained as a control group. Tissue samples and cloacae swaps of all birds were collected for

\footnotetext{
${ }^{1}$ Laboratorio de Patología Aviar, ${ }^{3}$ Laboratorio de Histología, Embriología y Patología Veterinaria, ${ }^{4}$ Laboratorio de Microbiología y Parasitología Veterinaria, Facultad de Medicina Veterinaria, Universidad Nacional Mayor de San Marcos, Lima

${ }^{2}$ E-mail: eliana.icochea@gmail.com
} 
histopathology analysis and virus isolation. Blood samples were collected during 5 weeks after the viral challenge to detect antibodies against NC virus using the hemaglutination inhibition (HI) test. In $40 \%$ of the inoculated birds was observed severe clinical signs and $20 \%$ mortality. The inoculated group registered an increase in the antibody level after day 7 post inoculation (MGT 6.1), reaching the highest level at 14 days post inoculation (MGT 29.9), whereas the control group did not register seroconversions. The viral isolation was obtained from cloacae swabs of the affected animals. The control group did not show signs of illness or histopathologycal changes.

Key words: Newcastle disease, quail, clinical signs, histopathology, antibody levels, virus isolation

\section{INTRODUCCIÓN}

El virus de la enfermedad de Newcastle (VENC) es uno de los patógenos más importantes y dañinos en la crianza de aves (Báez, 1994; Alexander, 1998b). Los brotes que se siguen reportando (OIE, 2001) demandan la evaluación de la virulencia de la enfermedad en especies aviares diferentes a pollos (Báez, 1994; King, 1999).

La codorniz japónica es un ave cuya crianza se ha popularizado en la costa peruana gracias a su rusticidad, fácil manejo y bajo costo de crianza. No obstante, se han reportado brotes de la enfermedad de Newcastle (ENC) en granjas de codornices en el Japón (OIE, 2001). En el Perú existen reportes sobre la ENC en diversas especies; sin embargo, la información es escasa sobre la susceptibilidad, respuesta inmune del virus y su patogenicidad, y no se dispone de trabajos previos en codornices. El presente estudio tuvo como finalidad evaluar el efecto clínico, serológico y patológico de la ENC inducida en forma experimental en codornices japónicas inoculadas con una cepa de virus velogénico viscerotrópico aislada de un brote en aves de riña.

\section{MatidRtales y Métodos}

Se emplearon 40 codornices japónicas hembras de 13 semanas de edad. Las aves fueron distribuidas en 2 grupos de 20 anima- les cada uno. El grupo desafiado fue inoculado con una cepa vENC, aislada de un brote enavesceriñadelazana, conurad $L_{50} 10^{7} /$ $\mathrm{ml}$, aplicándose una dosis de $75 \mu \mathrm{l}$ (3 gotas) por ave vía ocular y nasal. El grupo no inoculado permaneció como control. Las aves fueron clínicamente observadas hasta la quinta semana posterior al desafío.

Se colectaron muestras de tráquea, pulmón, proventrículo, molleja, intestino, tonsilas cecales, hígado, bazo, cerebro y cerebelo de las aves muertas durante el experimento y se fijaron en formol al 10\%. Además, se tomaron muestras de pulmón, tráquea e hisopados de cloaca de las aves de ambos grupos. Los tejidos obtenidos fueron procesados a fin de obtener una suspensión, la cual fue centrifugada y sometida a una solución con antibióticos y antimicóticos. Para la inoculación se emplearon huevos embrionados de 10 días de edad. Se inoculó $0.3 \mathrm{ml}$ del sobrenadante de cada muestra en la cavidad alantoidea de cinco huevos embrionados, los cuales fueron incubados a $37^{\circ} \mathrm{C}$ y examinados al ovoscopio dos veces al día para determinar la ocurrencia o no de mortalidad. Se registró la mortalidad por día, refrigerándose los embriones muertos. A los 7 días postinoculación, los embriones en los que no se registró mortalidad fueron retirados de la incubadora y refrigerados por 24 horas, para examinar la actividad hemaglutinante del fluido alantoideo mediante su enfrentamiento con una solución de glóbulos rojos al $0.75 \%$. 


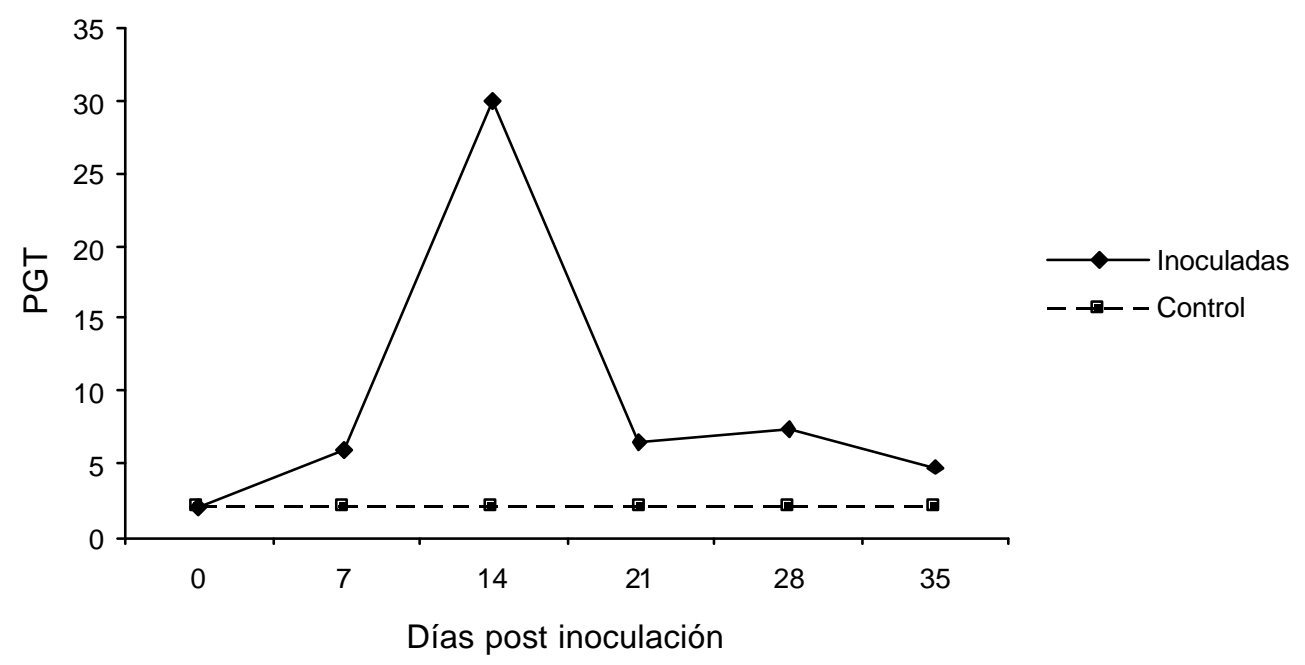

Figura 1. Detección de anticuerpos (PGT = Promedio geométrico de títulos) mediante la prueba de inhibición de la hemaglutinación en codornices inoculadas con una cepa vENC

Cuadro 1. Signos clínicos observados en codornices desafiadas con un virus velogénico viscerotrópico de ENC

\begin{tabular}{lccccccc}
\hline \multirow{2}{*}{ Signos clínicos } & \multicolumn{5}{c}{ Día postinoculación } & \multirow{2}{*}{ N. o de aves } \\
\cline { 2 - 6 } & 1 & 2 & 3 & 7 & 9 & $11-35$ & $(\mathrm{n}=20)$ \\
\hline Depresión & - & - & 5 & 8 & 4 & - & $8(40 \%)$ \\
Diarrea verdosa & - & - & 4 & 8 & 3 & - & $8(40 \%)$ \\
Edema facial & - & - & - & 2 & 4 & 2 & $420 \%)$ \\
Secreciones & - & - & - & 2 & 4 & 4 & $4(20 \%)$ \\
Estertores & - & - & 4 & 1 & - & - & $4(20 \%)$ \\
Boqueo & - & - & - & 2 & - & - & $2(10 \%)$ \\
Tortícolis & - & - & - & 2 & 4 & - & $4(20 \%)$ \\
Parálisis & - & - & - & 2 & 4 & - & $4(20 \%)$ \\
\hline
\end{tabular}

Cada semana se colectó $1.5 \mathrm{~cm}$ de sangre por animal al azar, de cada grupo, extraída de la vena braquial, desde una semana antes de la inoculación hasta la quinta semana postdesafío. Las muestras fueron analizadas mediante la prueba de inhibición de la hemaglutinación (IH) (Alexander 1998a), con el fin de detectar anticuerpos del virus de la ENC.

\section{Resultados}

Las aves desafiadas presentaron signos clínicos a partir del tercer día postinoculación, caracterizados por depresión severa, diarreas verdosas y dificultad respiratoria. A los 7 días postdesafío se observó el pico de infección afectando al $40 \%$ 
de las aves y la presencia de signos nerviosos (Cuadro 1).

En las aves postdesafio se observaron lesiones de importancia a partir del día 7, caracterizadas por hemorragias petequiales y equimóticas en intestino delgado y tonsilas cecales. Asimismo, se presentaron focos de necrosis en el bazo, incremento en el tamaño de las placas del Peyer y proventriculitis. Lesiones variables se observaron en cerebro, cerebelo, hígado, molleja, sacos aéreos y corazón. Las lesiones histopatológicas más importantes se observaron en el sistema nervioso asociadas a la presentación de manguitos perivasculares, edema, gliosis, satelitosis y neuronofagia. Mortalidad se observó únicamente en las aves desafiadas a partir del día 7 postdesafío afectando al $20 \%$.

Todas las aves inoculadas seroconvirtieron al final del experimento. Los títulos por grupo fueron expresados en Promedio Geométrico de Títulos (PGT) (Fig. 1). Se recuperó el virus de desafío a partir de las muestras de hisopado de cloaca de aves solo al $7^{\circ}$ día postinoculación. No se logró recuperar virus de las muestras de pulmón y tráquea.

\section{Discusión}

El grupo desafiado con la cepa de vvENC registró una mortalidad de $20 \%$, tasa inferior a la reportada en pollos de carne $(60 \%)$ (Silva, 1997) y en pollitas de postura comercial (100\%) (Alba e Icochea, 1999), empleando la misma cepa viral y demostrando una menor susceptibilidad de las codornices con respecto a pollos y pollitas de postura.

La mayoría de las codornices desafiadas presentaron signos clínicos a partir de los 3 días post-inoculación. Los signos fueron principalmente de tipo respiratorio y nervioso en los animales afectados de modo severo causándoles la muerte $(20 \%, 4 / 20)$, mientras que en el restante $80 \%$ (16/20) solamente se observó signos de tipo respiratorio y digesti- vo, llegándose a recuperar, como es señalado por Alexander (1998b).

Todas las codornices desafiadas seroconvirtieron (Fig. 1). Trabajos similares al presente, realizados por otros investigadores pero en palomas y tórtolas demostraron seroconversión después de la inoculación experimental; sin embargo, el máximo nivel de anticuerpos fue alcanzado en el caso de palomas en la $2^{\mathrm{a}}$ semana postinoculación obteniéndose un PGT 4.9 (Caballero, 2002), mientras que en tórtolas, el pico se obtuvo a los 21 días postinoculación (PGT 12.1, Vargas, 2002).

Existen diversos estudios sobre el comportamiento del vvENC en aves silvestres y algunos en codornices (Silva, 2004a,b); sin embargo, en ninguno se describen lesiones microscópicas como parte del estudio, limitándose a un seguimiento clínico incluyendo la mortalidad. En el presente estudio, histopatológicamente se observaron algunas lesiones relevantes, tanto en los animales que presentaron signos nerviosos como en los que no presentaron mayor sintomatología. En el sistema nervioso los hallazgos fueron similares a los descritos en pollos de carne afectados con vvENC (Alexander, 1998b) y a los encontrados en estudios previos en tórtolas y palomas inoculadas experimentalmente (Caballero, 2002; Vargas, 2002).

Los hallazgos patológicos macroscópicos fueron similares a los descritos en faisanes (Shivaprasad et al., 1999) y palomas inoculadas en forma experimental con el vvENC (Caballero, 2002); sin embargo, diferentes a las observaciones en tórtolas realizadas por Vargas (2002), quien no reportó lesiones macroscópicas a nivel digestivo.

En el análisis histopatológico del sistema nervioso se observó lesiones similares a las observadas en pollos de carne afectados con el virus de la ENC, tales como múltiples manguitos perivasculares a mononucleares y edema, vasculitis, gliosis, muerte neuronal, satelitosis y neuronofagia. Las lesiones des- 
critas en codornices se observaron también en palomas (Caballero, 2002), sin embargo, en tórtolas no se pudo encontrar la presencia de manguitos perivasculares en cerebro (Vargas, 2002). En la tráquea se observó acortamiento y pérdida ciliar del epitelio, al igual que en palomas y tórtolas (Riddell, 1996; Alexander, 1998b), a consecuencia de la agresión producida por la replicación viral posterior al ingreso del inóculo (Caballero, 2002; Vargas, 2002). En el bazo se observó una severa depleción linfoide y edema, similar a la presentada en pollos inoculados con APM1 aislado de palomas. Esta linfodepleción también se observó en palomas y tórtolas inoculadas con una cepa de vvENC (Caballero, 2002; Vargas, 2002).

La recuperación viral se logró a partir de hisopados de cloaca a los 7 días postinoculación. La literatura menciona que este tipo de muestra es una buena alternativa para el aislamiento del VENC, pues se logra aislar el patógeno antes que se presenten signos clínicos visibles. En el presente estudio, el 6.25\% de embriones inoculados murió y solo uno de ellos dio reacción positiva a la prueba de hemoaglutinación de líquido alantoideo; lo cual difiere con resultados de muestras provenientes de pollos que sufren la enfermedad, donde se encuentra hemoaglutinación positiva en la mayoría de las muestras. Por otro lado, Caballero (2002) y Vargas (2002), inoculando palomas y tórtolas, respectivamente, no lograron recuperar el virus de hisopados de cloaca, y el porcentaje de mortalidad embrionaria y reacción positiva a la prueba de hemoaglutinación de líquido alantoideo fue bajo.

Estos resultados estarían indicando que las codornices no solo son menos susceptibles a la enfermedad clínica, sino que, además, tienen una menor tasa de recuperación viral. Por lo tanto, este no sería un método recomendable para el aislamiento viral en codornices, a diferencia de la mayoría de galliformes, ya que habría una menor eliminación viral a través del tracto digestivo y menor contaminación ambiental. En el presente estudio se logró reproducir la enfermedad en codornices pero se obtuvo menor mortalidad y signos clínicos menos severos que en galliformes comerciales indicando que las codornices poseen una resistencia natural moderada a la enfermedad. Esto evidencia que el rol de las codornices en la epidemiología de la enfermedad sería menor en comparación al de otras especies.

\section{ConClusiones}

? La infección experimental de codornices (Coturnix coturnix japónica) con una cepa vvENC logró reproducir la enfermedad, causando una mortalidad del $20 \%$, y signos clínicos respiratorios, nerviosos y digestivos propios de la enfermedad.

? Se obtuvo una baja tasa de recuperación viral a partir de hisopados de cloaca a los siete días post inoculación.

? Todas las aves inoculadas desarrollaron niveles de anticuerpos contra el vvENC, demostrando seroconversión con la cepa de desafío y susceptibilidad a la infección subclínica.

\section{Limeratura Citada}

1. Alba M, Icochea E. 1999. Protección vacunal viva-oleosa en pollos broillers contra una cepa viscerotrópica velogénica del virus de la Enfermedad de Newcastle. En: XVI Congreso Latinoamericano de Avicultura, Lima: APA. p 270.

2. Alexander DJ. 1998a. Newcastle disease virus and other avian paramixoviruses. In: Laboratory manual for the isollation and identification of avian pathogens. $4^{\text {h }}$ ed. USA: AAAP Hunt Publishing Company. p 156-162. 
3. Alexander DJ. 1998b. Newcastle disease and other avian paramixoviridae infecctions. In: Calnek BW, Barnes HJ, Beard CW, McDonald LR, Saif YM (eds). Diseases of poultry, 10th ed. Iowa: Iowa State University Press. p 541-569.

4. Báez J. 1994. Enfermedad de Newcastle. En: Patología de la aves. Cap 2. México DF: Trillas. p 14-18.

5. Caballero F. 2002. Evaluación experimental de la patogenicidad de un virus velogénico viscerotrópico de la enfermedad de Newcastle y su respuesta inmune humoral en aves columbiformes. Tesis de Médico Veterinario. Lima: Facultad de Medicina Veterinaria, Univ Nacional Mayor de San Marcos. 45 p.

6. King D. 1999. Enfermedad de Newcastle. En: XVI Congreso Latinoamericano de Avicultura, Lima: APA. $p$ 56-61.

7. OIE Disease Information Report. 2001. Newcastle disease in Japan. Summary of selected disease events: April-June 2001. [Internet], [21 January 2002]. Disponible: http://www.oie.int/ eng/ info.htm

8. Riddell C. 1996. Avian histopathology. $2^{\text {nd }}$ ed. Florida, USA: American Association of Avian Pathologist. 360 p.
9. Shivaprasad H, Rupier D, Woolcock P, Woods L. 1999. An outbreak of Newcastle disease. In: Proc Western Poultry Disease Conference. Davis, California: University of California.

10. Silva A. 1997. Inmuno-protección por vacuna oleosa y/o viva frente a una infección experimental de la enfermedad de Newcastle en pollos de carne. Tesis de Médico Veterinario. Lima: Facultad de Medicina Veterinaria, Univ Nacional Mayor de San Marcos. 50 p.

11. Silva F. 2004a. Evaluation of different programs of Newcastle disease vaccination in Japanese quail (Coturnix coturnix japonica). Int J Poultry Sci 3(5): 354-356.

12. Silva F. 2004b. Japanese quail (Coturnix coturnix japonica) as Newcastle disease virus carrier. Int $\mathbf{J}$ Poultry Sci 3(7): 483-484.

13. Vargas J. 2002. Patogenicidad y respuesta serológica de las tórtolas (Eupelia cruziana) frente a un virus de la enfermedad de Newcastle. Tesis de Médico Veterinario. Lima: Facultad de Medicina Veterinaria, Univ Nacional Mayor de San Marcos. 45 p. 